\title{
Disorders of sex development: a study of 194 cases
}

\author{
R Walia', M Singla' ${ }^{1}$ K Vaiphei ${ }^{2}$, S Kumar ${ }^{3}$ and A Bhansali ${ }^{1}$ \\ ${ }^{1}$ Department of Endocrinology, Postgraduate Institute of Medical Education \& Research, Chandigarh, India \\ ${ }^{2}$ Department of Histopathology, Postgraduate Institute of Medical Education \& Research, Chandigarh, India \\ ${ }^{3}$ Department of Urology, Postgraduate Institute of Medical Education \& Research, Chandigarh, India \\ Correspondence should be addressed to A Bhansali: anilbhansaliendocrine@gmail.com
}

\begin{abstract}
Objective: To study the clinical profile and the management of patients with disorders of sex development (DSD).

Design and setting: Retrospective study from a tertiary care hospital of North India. Methods and patients: One hundred ninety-four patients of DSD registered in the Endocrine clinic of Postgraduate Institute of Medical Education and Research, Chandigarh between 1995 and 2014 were included.

Results: One hundred and two patients (52.5\%) had 46,XY DSD and seventy-four patients (38.1\%) had 46,XX DSD. Sex chromosome DSD was identified in seven $(3.6 \%)$ patients. Of 102 patients with 46,XY DSD, 32 (31.4\%) had androgen insensitivity syndrome and $26(25.5 \%)$ had androgen biosynthetic defect. Of the 74 patients with 46,XX DSD, 52 (70.27\%) had congenital adrenal hyperplasia (CAH) and eight (10.8\%) had ovotesticular DSD. Five patients with sex chromosome DSD had mixed gonadal dysgenesis. Excluding $\mathrm{CAH}$, majority of the patients (90\%) presented in the postpubertal period. One-fourth of the patients with simple virilising $\mathrm{CAH}$ were reared as males because of strong male gender identity and behaviour and firm insistence by the parents. Corrective surgeries were performed in twenty patients (20\%) of 46,XY DSD without hormonal evaluation prior to the presentation. Conclusion: Congenital adrenal hyperplasia is the most common DSD in the present series. Most common XY DSD is androgen insensitivity syndrome, while CAH is the most common XX DSD. Delayed diagnosis is a common feature, and corrective surgeries are performed without seeking a definite diagnosis.
\end{abstract}

\author{
Key Words \\ - disorders of sex \\ development \\ - congenital adrenal \\ hyperplasia \\ - androgen insensitivity \\ syndrome \\ - androgen biosynthetic \\ defect
}

Endocrine Connections (2018) 7, 364-371

\section{Introduction}

Disorder of sex development (DSD) is defined as congenital condition in which the development of chromosomal, gonadal or anatomic sex is atypical (1). The incidence of DSD is $1: 4500$ to $1: 5000$ live births $(2,3)$. It is a social emergency as the decision-making in relation to sex assignment has been perceived as extremely disturbing and difficult to both families and health care professionals (4). Management of patients with DSD requires a co-ordinated approach by a team of an endocrinologist, a paediatrician, a surgeon, a radiologist, with good laboratory setup. Virilization of external genitalia at birth depends upon intra-uterine exposure to androgens which can be testicular, adrenal or sometimes exogenous in origin. The presence of Mullerian structures in general suggests either a female genetic sex or gonadal dysgenesis in a genetic male with inadequate production of anti-Mullerian hormone (AMH). Sex of rearing depends on the genetic sex, degree of virilization of external genitalia, prospects of restoring normal appearance of external genitalia and fertility and parent's/patient's preferences.

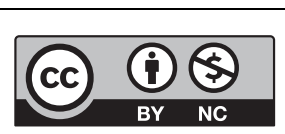

This work is licensed under a Creative Commons Attribution-NonCommercial 4.0 International License. 
Genital surgery is often required; however, the type and time of surgery are still debatable (5). Most of the data on this condition is from the western countries. There is a general paucity of information on the clinical profile of children with DSD in South East Asia, being available mostly in the form of case reports and small case series $(6,7,8,9,10,11,12,13)$. We present the clinical profile, diagnosis and management of 194 patients with DSD.

\section{Methods}

The data of 194 patients of DSD who were registered in the Endocrine Clinic of Post Graduate Institute of Medical Education and Research between 1995 and 2014 were analysed retrospectively. The study was approved by Institute Ethics Committee of Post Graduate Institute of Medical Education and Research (INT/IEC/2015/211). Consent was obtained from each patient after full explanation of the purpose and nature of all procedures used. Features that suggest the diagnosis of DSD include overt genital ambiguity, apparent male genitalia with nonpalpable testis, micropenis, isolated perineal hypospadias, apparent female genitalia with clitoromegaly, posterior labial fusion, inguinal/labial mass, family history of DSD (e.g. complete androgen insensitivity syndrome) and genital/karyotype discordance (1). Current classification of DSD includes patients with Turner's syndrome and Klinefelter's syndrome (1). However, we have not included them in our series as they usually do not have genital ambiguity. A thorough elicitation of history and detailed clinical examination was done in all the patients. The hormonal profile included luteinizing hormone (LH), follicle-stimulating hormone (FSH), testosterone (T) and dihydrotestosterone (DHT), androstenedione (A) and unstimulated and/or stimulated 17-hydroxy progesterone 17(OH) P levels (where indicated). Congenital adrenal hyperplasia was diagnosed if unstimulated and/or stimulated $17(\mathrm{OH})$ P levels of $>100 \mathrm{ng} / \mathrm{mL}$ after $250 \mu \mathrm{g}$ ACTH bolus (14). Human chorionic gonadotropin (hCG) stimulation was done by administering 1500 units per square metre of body surface area of hCG intramuscularly for 3 days and sample for stimulated $\mathrm{T}$ and DHT was collected $24 \mathrm{~h}$ after the last dose. The response was considered adequate if the stimulated $\mathrm{T}$ level was at least $9 \mathrm{nmol} / \mathrm{L}$ (15). Androgen biosynthetic defect was diagnosed with low testosterone and high $\mathrm{LH}$, FSH values during pubertal and post-pubertal period with $\mathrm{T} / \mathrm{A}$ ratio $<0.8$ in response to hCG stimulation (15). A T/DHT ratio of greater than 30 was considered suggestive of

http://www.endocrineconnections.org https://doi.org/10.1530/EC-18-0022
(C) 2018 The authors Published by Bioscientifica Ltd
$5 \alpha$-reductase deficiency (5- $\alpha \mathrm{RD})$ (15). The diagnosis of androgen insensitivity was based on the presence of high basal LH, FSH and T on either side of the "window period'. Gender identity, role and behaviour were assessed with the help of clinical psychologist. LH, FSH and T hormones were measured with radioimmunoassay till 2006 (BARC, Mumbai India) with intra- and interassay coefficient of variation of $<8 \%$ with reference range of 5-15 mLIU/mL for LH\& FSH, 9-27 nmol/L for T. After 2006, electrochemiluminescence immunoassay (ECLIA) (ELECSYS-2010, Roche Diagnostics) was used. The normal range of this assay for $\mathrm{LH}, \mathrm{FSH}, \mathrm{T}$ and $\mathrm{A}$ are $1.7-8.6 \mathrm{IU} / \mathrm{L}$, $1.5-12.4 \mathrm{IU} / \mathrm{L}, \quad 9.9-27.8 \mathrm{nmol} / \mathrm{L}$ and $175-768 \mathrm{nmol} / \mathrm{L}$ respectively with intra-assay and interassay $\mathrm{CV}$ of $<6 \%$ and $<5.1 \%$, respectively. $17(\mathrm{OH}) \mathrm{P}$ and DHT were estimated by radioimmunoassay and enzyme immunoassay, respectively. Ultrasonography and/or magnetic resonance imaging was done to look for Mullerian structures, ovaries and undescended testis. Laparoscopy/exploratory laparotomy and genitoscopy/genitogram were done when required. Diagnosis of ovotesticular DSD was confirmed by histopathological examination of the gonads. Karyotype was done in the patients, as indicated. Sex assignment was done considering the gender identity, sex of rearing and after discussing the fertility prospects with the parents and the patients.

\section{Results}

Out of the 194 patients, 102 had 46,XY DSD and 74 patients had 46,XX DSD. Sex chromosome DSD was identified in seven patients. In 11 patients, the etiological diagnosis could not be made. The various aetiologies of DSD are shown in Table 1. The age of presentation in our series varied from neonatal period to 65 years. Fiftytwo patients had congenital adrenal hyperplasia $(\mathrm{CAH})$ making it the most frequent cause of DSD (Table 2).

\section{6,XY DSD}

The most common cause for 46,XY DSD was androgen insensitivity syndrome (AIS), diagnosed in thirtytwo patients (Table 3). Three patients with complete androgen insensitivity syndrome (CAIS) had female genitalia and presented during adolescence age with primary amenorrhea, although had spontaneous breast development. Gonads were palpable in inguinal region in all these patients and gonadectomy was performed post-pubertally. Following gonadectomy, these patients 
Table 1 Overview of various aetiologies in 194 patients of DSD.

\begin{tabular}{|c|c|c|}
\hline 46,XX DSD & $\boldsymbol{n}(\%)$ & 46,XY DSD \\
\hline $\mathrm{CAH}$ & $52(70.3)$ & Androgen insensitivity syndrome \\
\hline Ovotesticular & $8(10.8)$ & Androgen biosynthetic defect \\
\hline MRKH & $9(12.1)$ & Gonadal dysgenesis \\
\hline Gonadal dysgenesis & $3(4.1)$ & $5 \alpha$-reductase deficiency \\
\hline Testicular & $1(1.4)$ & Idiopathic Hypospadias \\
\hline Androgen exposure in utero & $1(1.4)$ & $\begin{array}{l}\text { Vanishing testis syndrome } \\
\text { B/L cryptorchidism } \\
\text { Ovotesticular } \\
\text { Associated with other anomalies }\end{array}$ \\
\hline Undefined & & \\
\hline
\end{tabular}

\begin{tabular}{|c|c|c|}
\hline$n(\%)$ & Sex chromosome DSD & $n(\%)$ \\
\hline $32(31.4)$ & Mixed gonadal dysgenesis & $5(71.4)$ \\
\hline $26(25.5)$ & Ovotesticular & $1(14.3)$ \\
\hline $11(10.8)$ & Super male & $1(14.3)$ \\
\hline $9(8.8)$ & & \\
\hline $9(8.8)$ & & \\
\hline $7(6.8)$ & & \\
\hline $2(1.9)$ & & \\
\hline 2 (1.9) & & \\
\hline $4(3.9)$ & & \\
\hline $11(5.7)$ & & \\
\hline
\end{tabular}

were started on oestrogen replacement therapy. Twenty patients having partial androgen insensitivity (PAIS) presented with gynaecomastia and varying genital undervirilization in the form of hypospadias, micropenis, bifid scrotum and cryptorchidism. Median age of presentation was twenty years. Seventeen patients were reared as males and three were reared as females, concordant with their gender identity. Corrective surgeries for hypospadias and orchidopexy were performed and testosterone supplementation was started to enhance virilisation in patients with male sex of rearing. Patients with female sex of rearing underwent gonadectomy followed by oestrogen replacement therapy. Out of the twenty patients, eight patients had undergone corrective surgeries for hypospadias and gynaecomastia without the definite diagnosis prior to the presentation in our institute. Nine patients with minimal androgen insensitivity syndrome (MAIS) presented with primary infertility and/or gynaecomastia. Median age of presentation in these patients was 32 years. The oldest patient presented at 65 years of age with gynaecomastia. Reduction mammoplasty was performed in these patients. Family history was positive in one patient with CAIS and in three patients with PAIS.

Twenty-six patients had androgen biosynthetic defect due to $17 \beta$-hydroxysteroid dehydrogenase type 3 (HSD17B3) deficiency. Seventeen were reared as males and presented at median age of 22 years with varying degree of genital ambiguity. Out of these, three patients were diagnosed in childhood based on hCG-stimulated testosterone:androstenedione ratio. These patients required testosterone replacement post-pubertally. Nine patients were reared as females and presented postpubertally with varying degree of virilisation and genital ambiguity. All of them underwent orchidectomy (Fig. 1) followed by oestrogen replacement therapy. Associated anomalies included left hip dysplasia, acromelia and congenital cyanotic heart disease in one patient each.

Nine patients had $5 \alpha$-reductase deficiency. Three patients who were reared as females had clitoromegaly detected prepubertally. These patients had significant virilisation during puberty and change of gender identity to male. Six were reared as males and presented with micropenis with varying degree of hypospadias. These patients were treated with dihydrotestosterone gel. History of consanguinity was present in two patients.

Eleven patients had testicular dysgenesis. Three patients with complete gonadal dysgenesis had female genitalia and presented with primary amenorrhea and absent secondary sexual characters. Serum gonadotropins were elevated. Eight patients with partial gonadal dysgenesis presented with varying degree of genital ambiguity. Two patients were siblings, presenting at the age of thirteen and fifteen years respectively. All were reared as females. Mullerian derivatives were present on imaging and karyotype was 46,XY. Bilateral gonadectomy

Table 2 Clinical profile of patients with CAH.

\begin{tabular}{l}
\hline Type of CAH \\
\hline 21-hydroxylase deficiency CAH \\
Numbers of patients \\
Median age at presentation (months) \\
Clinical presentation \\
Median 17-hydroxyprogesterone levels (ng/mL) \\
Gender assignment
\end{tabular}

Gender assignment

\section{Salt wasting}

10

$0.4(0.25-1.5)$

Vomiting, dehydration, ambiguous genitalia

$383(142-1030)$

All females

\section{Simple virilizing}

42

$2(1-240)$

Ambiguous genitalia, heterosexual precocious puberty 205 (120-754)

32 females

10 males http://www.endocrineconnections.org https://doi.org/10.1530/EC-18-0022 (c) 2018 The authors Published by Bioscientifica Ltd
This work is licensed under a Creative Commons Attribution-NonCommercial 4.0 International License. 
Table 3 Clinical profile of patients with 46,XY DSD with androgen insensitivity syndrome.

\begin{tabular}{|c|c|c|c|c|c|}
\hline Type & No. & Clinical presentation & Gender assignment & $\begin{array}{c}\text { Median age at } \\
\text { presentation (years) }\end{array}$ & $\begin{array}{c}\text { Positive family } \\
\text { history }\end{array}$ \\
\hline $\begin{array}{l}\text { Complete androgen } \\
\text { insensitivity syndrome }\end{array}$ & 3 & Primary amenorrhea & All females & $18(18-20)$ & 1 \\
\hline $\begin{array}{l}\text { Partial androgen } \\
\text { insensitivity syndrome }\end{array}$ & 20 & $\begin{array}{l}\text { Hypospadias, micropenis, bifid } \\
\text { scrotum, clitoromegaly }\end{array}$ & 17 males, 3 females & $20(16-22)$ & 3 \\
\hline $\begin{array}{l}\text { Minimal androgen } \\
\text { insensitivity syndrome }\end{array}$ & 9 & Gynaecomastia, infertility & All males & $32(22-65)$ & Nil \\
\hline
\end{tabular}

was performed in all cases because of the risk of malignancy. All these patients were put on oestrogen replacement therapy.

Two patients presenting with genital ambiguity had ovotesticular DSD. One patient presented at the age of fourteen years and was reared as female but had gender identity of male. After appropriate counselling, the ovarian and dysgenetic tissues were removed to prevent further oestrogenization, and testosterone supplementation was started to complete pubertal development (Fig. 2 and Table 4).

Seven patients had vanishing testes syndrome. They had unambiguous male genitalia with non-palpable gonads that were not localized even after laparoscopy. Serum gonadotropins levels were elevated and testosterone response to hCG was flat. Age appropriate testosterone replacement was started in all these patients, and testicular prosthesis was implanted in three patients. Nine patients with perineal hypospadias had normal gonadotropins and testosterone, with completely descended scrotal

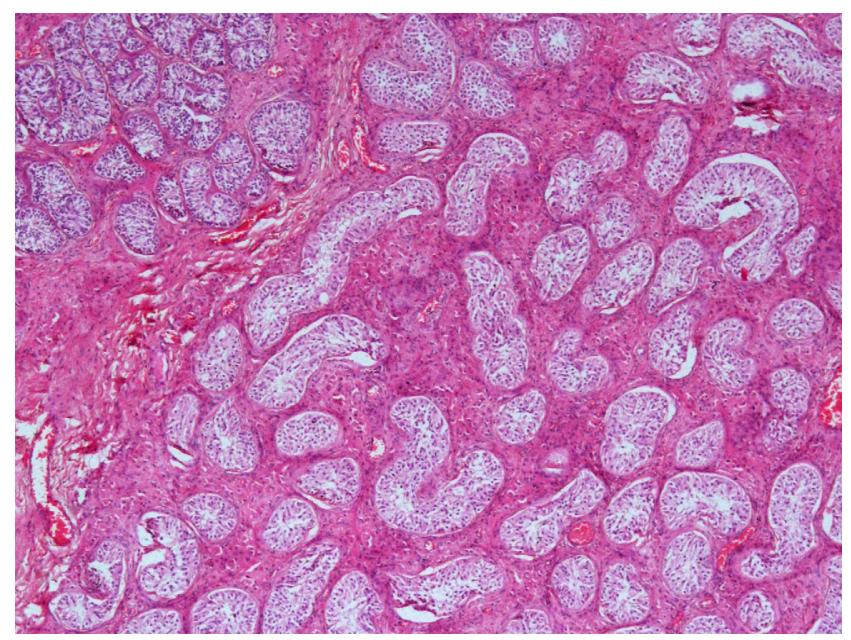

\section{Figure 1}

Low power photomicrograph to show seminiferous tubules with Sertoli cells only with prominent interstitial Leydig cells. At the left upper corner is the collection of seminiferous tubules containing germ cells (H\&E, $\times 50)$. testis. They were labelled as having isolated hypospadias. Corrective surgery was performed in these patients.

Four patients had genital ambiguity associated with other congenital anomalies like talipes equino varus, polydactyly, acromelia, thumb aplasia, ventricular septal defect and aqueductal stenosis causing hydrocephalus. Hormonal investigations were normal in all of them, and the genital anomaly was considered as a part of other somatic defects.

\section{$46, X X$ DSD}

The most common cause for 46,XX DSD was congenital adrenal hyperplasia. Fifty-two patients had classical CAH (Table 2). All of them had 21-hydroxylase deficiency. Ten patients had salt wasting CAH. They were diagnosed at birth and were assigned female sex of rearing. Forty-two patients had simple virilising CAH. Out of these, thirty-three

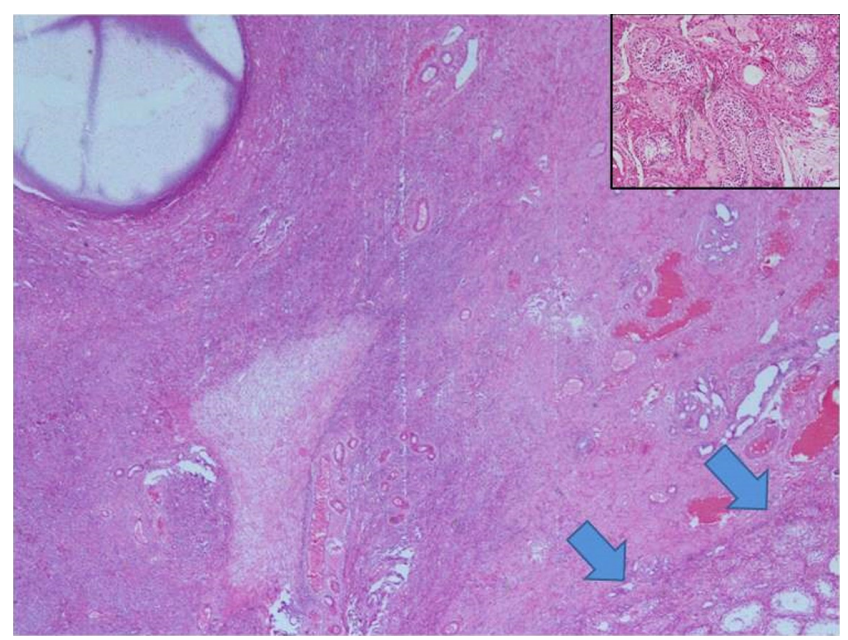

\section{Figure 2}

Low power photomicrograph showing both ovarian and testicular tissue in one low power field area. The Graafian follicle is seen at upper and left hand side of the picture with ovarian stroma. Seminiferous tubules are seen at the lower part of the picture and highlighted by thick arrows $(H \& E, \times 50)$. The same has so been given in the inset showing seminiferous tubules with thickened basement membrane interspersed with Leydig cell (H\&E, $\times 250)$.

$$
\begin{array}{lr}
\text { http://www.endocrineconnections.org } & \text { ○ } 2018 \text { The authors } \\
\text { https://doi.org/10.1530/EC-18-0022 } & \text { Published by Bioscientifica Ltd }
\end{array}
$$


Table 4 Clinical profile of 11 patients with ovotesticular DSD.

\begin{tabular}{lll} 
& & \\
\cline { 1 - 1 } $2 / 12$ & & Ambiguity \\
9 & & Ambiguity \\
1.5 & & Ambiguity \\
$2 / 12$ & Ambiguity \\
$2 / 12$ & Ambiguity \\
41 & Abdominal pain, mass \\
1.5 & Right inguinal hernia \\
17 & Ambiguity \\
23 & Ambiguity \\
14 & Ambiguity \\
25 & Ambiguity
\end{tabular}

\begin{tabular}{l} 
Karyotype \\
\hline $46, X X$ \\
$46, X X$ \\
$46, X X$ \\
$46, X X$ \\
$46, X Y$ \\
$46, X X$ \\
$46, X X$ \\
$46, X Y / 47, X X Y$ \\
$46, X X$ \\
$46, X Y$ \\
$46, X X$ \\
\hline
\end{tabular}

\begin{tabular}{l} 
Gender identity \\
\hline Female \\
Male \\
Female \\
Male \\
Male \\
Male \\
Female \\
Male \\
Male \\
Male \\
Male
\end{tabular}

\begin{tabular}{l} 
Sex of rearing \\
\hline Female \\
Male \\
Female \\
Male \\
Male \\
Male \\
Female \\
Male \\
Male \\
Female \\
Male
\end{tabular}

\begin{tabular}{ll}
\hline Gonad & \\
\cline { 1 - 1 } Right & Left \\
\cline { 1 - 1 } Testis & Ovary \\
Ovotestis & Ovary \\
Testis & Ovotestis \\
Ovotestis & Ovary \\
Ovary & Testis \\
Ovotestis & Ovary \\
Ovotestis & Ovary \\
Ovary & Ovotestis \\
Testis & Ovotestis \\
Ovotestis & Ovary \\
Testis & Ovotestis \\
\hline
\end{tabular}

patients were diagnosed at birth due to ambiguous genitalia. Seven patients presented with heterosexual precocious puberty. Two patients of simple virilising CAH presented as late as third decade of life, one with primary infertility and bilateral adrenal masses, and another with primary infertility and short stature. Ten patients with simple virilising $\mathrm{CAH}$ were reared as males because of Prader grade $\mathrm{V}$ virilisation, delayed diagnosis, strong male gender identity and behaviour and firm insistence by the parents. They underwent laparotomy and removal of the female internal genital organs. Testicular prosthesis was implanted in three patients. Adrenal myelolipoma in the setting of adrenal nodularity was observed in one patient with heterosexual precocious puberty. Both the patients with primary infertility conceived after starting treatment with hydrocortisone. Treatment for $\mathrm{CAH}$ also led to regression in the size of adrenal masses in the patient. One patient with salt wasting $\mathrm{CAH}$ had Down syndrome. Genetic analysis was performed in thirty patients (16).

Eight patients had ovotesticular DSD. Five of them were reared as males. They presented with varying degree of genital ambiguity and breast development. In all cases, gender identity was consistent with sex of rearing. After appropriate counselling, the discordant gonad and dysgenetic tissue was removed, and the patients were started on appropriate gonadal hormone replacement. One patient presented with lower abdominal mass and on probing, history of cyclical haematuria was present. He underwent surgery and the mass was found to be leiomyomata of the uterus. The most common gonad was ovotestis being present in 7 of 16 gonads (43.7\%). The details of age and mode of presentation, distribution of internal genitalia and sex of rearing of patients with ovotesticular DSD are presented in the Table 4.

One patient with 46,XX testicular DSD (XX male) presented with primary amenorrhea. One dysgenetic testis was found in inguinal region while the other could

$$
\begin{array}{lr}
\text { http://www.endocrineconnections.org } & \text { ○ } 2018 \text { The authors } \\
\text { https://doi.org/10.1530/EC-18-0022 } & \text { Published by Bioscientifica Ltd }
\end{array}
$$

not be localized. She was reared as a female and therefore started on oestrogen replacement therapy.

Nine patients with Mayer-Rokitansky-Kuster Hauser syndrome had primary amenorrhea and well-developed secondary sexual characters. Imaging (ultrasonography and/or computed tomogram) revealed Mullerian agenesis.

Three patients with complete gonadal dysgenesis presented with lack of secondary sexual characters with absent pubertal spurt of growth. One patient presented with posterior labial fusion and had history of androgen exposure in utero. She attained menarche at the age of 16 years with regular menstrual cycles and no other features of virilization. She underwent corrective surgery for posterior labial fusion.

\section{Sex chromosome DSD}

Five patients had mixed gonadal dysgenesis. Median age at presentation was 10 years. Testis was palpable unilaterally in three patients. On laparoscopy, there was dysgenetic testis on one side and streak gonad on the other with the presence of Mullerian derivatives. Varying degrees of labioscrotal fusion and hypospadias were recorded in these patients requiring genitoplasty. Karyotype was $45, \mathrm{X} / 46, \mathrm{XY}$ in all these subjects.

One patient of ovotesticular DSD presented with penoscrotal hypospadias and palpable gonad in right scrotum. There was a mass palpable in left inguinal region. Patient underwent laparotomy and removal of both gonads and the inguinal mass. Histopathology showed right testis and left intra-abdominal haemorrhagic corpus luteal cyst. Mass in inguinal region was uterine adenomyosis. His karyotype was $46, \mathrm{XY} / 47, \mathrm{XXY}$ and was reared as male.

In 11 patients, the disorder could not be defined. Gonadoblastoma was found in one patient who presented at the age of 40 years with lower abdominal 
mass. She was reared as female and had features of virilization. External genitalia showed perineoscrotal hypospadias and bilateral non-palpable gonads. Her karyotype was 46 ,XO. She had elevated gonadotropins and had no Mullerian structures and the other gonad could not be identified on laparotomy. She was classified as undefined case.

\section{Discussion}

In our series of 194 patients with DSD, 46,XY DSD was more common than 46 , XX DSD, which is consistent with the previously reported case series $(8,9,10,12)$. However, in a case series from Saudi Arabia, 53 (65.4\%) were genetically females $(46, \mathrm{XX})$, and 28 (34.6\%) were having a male genetic sex $(46, X Y)(13)$. The most frequent cause of DSD was congenital adrenal hyperplasia due to classic 21-hydroxylase deficiency, being consistent with most of the case series $(6,7,8,9,10,12)$.

Most common XY DSD is androgen insensitivity syndrome, while CAH is the most common XX DSD. In a series by Joshi and coworkers (8), androgen insensitivity syndrome was the most common aetiology (28\%) of XY DSD while all 46,XX DSD were CAH. Similarly, in a case series from Thailand (10), all patients with 46,XX DSD had CAH while $46.8 \%$ of 46 , XY DSD had either androgen insensitivity syndrome or $5 \alpha$-reductase deficiency.

Congenital adrenal hyperplasia is the most common cause for DSD worldwide. It is usually diagnosed at birth during routine new-born screening with estimation of 17-hydroxy progesterone (14). However, in India due to lack of routine new-born screening, patients with $\mathrm{CAH}$ are usually diagnosed late when they present with salt wasting and/or virilization, and many times, it is a medical emergency (1). Ten patients had salt wasting $\mathrm{CAH}$, which is a life-threatening condition. One should always consider this possibility in a child with vomiting and failure to thrive as this is a treatable condition especially in setting like ours where screening for $\mathrm{CAH}$ is not routinely done. All the patients with CAH in our series had classic 21-hydroxylase deficiency. Rare complications like bilateral adrenal nodular masses was observed in two of the patients who received treatment at a later age. One patient developed adrenal myelolipoma in the setting of adrenal nodularity (17). However, bilateral adrenal incidentalomas do not reliably predict $\mathrm{CAH}$, but if present with hyperandrogenism, testing may be justified (18). Almost one-fourth of the CAH patients who were genetic females were reared as males. Severity of virilization of genitalia and parental insistence for rearing as a male in a male-dominated society significantly influenced the choice of sex of rearing. In all these patients, gender identity and role were male, strengthening the hypothesis that prenatal exposure to androgens is important in masculinizing the brain (19). Delayed presentation and bias towards male sex of rearing are peculiar to our setting as reported earlier $(6,7,8,9)$. All of them underwent laparotomy and removal of female internal genital organs. Implantation of testicular prosthesis was done in 3 patients. Periodic follow-up is essential as large studies have documented increased risk of hypertension, cardiovascular morbidity and excess mortality in patients with CAH $(20,21,22)$.

Androgen insensitivity syndrome was the most common single entity that resulted in male under masculinisation as previously reported (8). Presentation in CAIS in our study was by primary amenorrhea despite presence of inguinal swellings since birth. It emphasizes the importance of considering AIS in any female infant with inguinal hernia. Estimates of the incidence of AIS in such infants have ranged from 1-12\% (23). Family history could be elicited in only four patients suggesting greater etiological heterogeneity and the sporadic origin of AIS as reported previously (24). All patients with androgen insensitivity syndrome maintained their gender role and identity after entering into puberty, which was assigned to them during infancy.

HSD17B3 deficiency is an autosomal recessive disorder characterised by ambiguous genitalia and significant virilisation during puberty due to conversion of androstenedine to testosterone by extra-gonadal HSD17B isoenzymes or residual HSD17B3 activity (25). Puberty-dependent virilization pushes many patients to change their social sex to male at puberty. The consequent female-to-male gender reassignment has been reported in $39-64 \%$ of cases (26). However, change of gender identity was not noticed in any patient with female sex of rearing in our series.

Even though $5 \alpha$-reductase deficiency is considered to be a common cause of $46, \mathrm{XY}$ DSD, we found only nine patients in our group. History of consanguinity was documented in two patients. Clitoromegaly and micropenis with hypospadias were the most common phenotypes, which corroborated to the results from a multinational study of 55 patients (27). Early diagnosis is mandatory in these patients to prevent psychological suffering, which occurs when a female-to-male gender identity switch is requested, as seen in three patients in our series. 
All patients with XY dysgenetic testis were reared as female. Two siblings were having partial gonadal dysgenesis, suggesting possible autosomal inheritance. Considering the high incidence of gonadoblastoma and the early occurrence of dysgerminoma, bilateral gonadectomy is recommended (28). Three patients with $\mathrm{XX}$ gonadal dysgenesis presented with short stature and absent secondary sexual characters. These patients require lifelong hormone replacement therapy.

All patients with ovotesticular DSD presented with ambiguous genitalia except the one who presented with lower abdominal mass, which was found out to be leiomyomata of the uterus (29). The aetiology of lower abdominal mass in ovotesticular DSD is usually germ cell tumour. In most cases, gender identity was consistent with sex of rearing. 46,XX was the most common karyotype (72\%) in our series, which is consistent with the previously reported data worldwide. In a series of 96 ovotesticular DSD cases from Africa, 96.9\% showed 46,XX karyotype while only $7 \%$ of 283 cases worldwide had 46,XY karyotype (30). Gonads with testicular tissue were more frequent on the right side of the body, while pure ovarian tissue was more common on the left.

All patients of mixed gonadal dysgenesis presented with genital ambiguity and none of them had UllrichTurner manifestations. This is in contrast to the study from Mexico in which 10 out of 16 patients, had clinical features reminiscent of Turner syndrome (31). The $45, \mathrm{X} / 46$, XY karyotype was the most frequent karyotype, which is consistent with the published literature.

$46, \mathrm{XX}$ testicular DSD is a rare entity, and we had only one patient in this series (32). Majority of patients with this diagnosis are reared as male $(33,34)$. Our patient was reared as female and presented with primary amenorrhea and infertility.

Four patients presented with ambiguous genitalia associated with other congenital malformations, in a series from Iran (35), 2.6\% of subjects with ambiguous genitalia had congenital malformation.

The strengths of the study are large number of subjects, detailed clinical profile with biochemical and histopathological confirmation. Limitations of the study include retrospective design and lack of detailed genetic/ molecular workup.

In conclusion, 21-hydroxylase deficiency congenital adrenal hyperplasia is the most common DSD in the present series. Most common XY DSD is androgen insensitivity syndrome, while CAH is the most common XX DSD. Parental insistence for rearing as a male in a male-dominated society significantly influences the choice of sex of rearing. Delayed diagnosis is a common feature and corrective surgeries are performed without seeking a definite diagnosis prior to the referral to our institute.

\section{Declaration of interest}

The authors declare that there is no conflict of interest that could be perceived as prejudicing the impartiality of the research reported.

\section{Funding}

This work did not receive any specific grant from any funding agency in the public, commercial, or not-for-profit sector.

\section{Author contribution statement}

A B supervised the work and analysed the data, S K performed corrective surgery, K V analysed histopathological data, R W collected and analysed the data and edited the manuscript and M S analysed the data and wrote the paper.

\section{Acknowledgements}

The authors are very grateful to the patients and their families for their contribution to the study.

\section{References}

1 Lee PA, Honk CP, Ahmed SF \& Hughes IA. Consensus statement on management of intersex disorders. Pediatrics 2006118 e488-e500. (https://doi.org/10.1542/peds.2006-0738)

2 Thuyen U, Lanz K, Holterhus PM \& Hiort O. Epidemiology and initial management of ambiguous genitalia at birth in Germany. Hormone Research in Paediatrics 200666 195-203. (https://doi. org/10.1159/000094782)

3 Hamerton JL, Canning N, Ray M \& Smith S. A cytogenetic survey of 14,069 newborn infants. Incidence of chromosome abnormalities. Clinical Genetics 19758 223-243. (https://doi. org/10.1111/j.1399-0004.1975.tb01498.x)

4 Hyun G \& Kolon TF. Practical approach to intersex in the newborn period. Urologic Clinics of North America 200431 435-443. (https:// doi.org/10.1016/j.ucl.2004.04.008)

5 Warne GL \& Raza J. Disorders of sex development, their presentation and management in different cultures. Reviews in Endocrine and Metabolic Disorders 20089 227-236. (https://doi.org/10.1007/s11154008-9084-2)

6 Ammini AC, Gupta R, Kapoor A, Karak A, Kriplani A, Gupta DK \& Kucheria K. Etiology, clinical profile, gender identity and long-term follow up of patients with ambiguous genitalia in India. Journal of Pediatric Endocrinology and Metabolism 200215 423-430. (https://doi. org/10.1515/JPEM.2002.15.4.423)

7 Rajendran R \& Hariharan S. Profile of intersex children in south India. Indian Paediatrics 199532 666-671.

8 Joshi RR, Rao S \& Desai M. Etiology and clinical profile of female genitalia - an overview of 10 years of experience. Indian Paediatrics 200743 974-978.

9 Gupta DK \& Menon PSN. Ambiguous genitalia: an Indian perspective. Indian Journal of Pediatrics 199764 189-194. (https://doi. org/10.1007/BF02752442)

10 Nimkam S, Likitmoskul S, Sangecharoenkit P, Pathomvanich A, Sawathiparnich P, Wacharasindhu S, Punnakanta L, Angsusingha K \& Tuchinda C. Ambiguous genitalia: an overview of 22 years experience

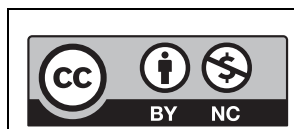

This work is licensed under a Creative Commons Attribution-NonCommercial 4.0 International License. 
and the diagnostic approach in the pediatric department, Siriraj Hospital. Journal of the Medical Association of Thailand 200285 496-505.

11 Atta I, Ibrahim M, Parkash A, Lone SW, Khan YN \& Raza J. Etiological diagnosis of undervirilized male/XY disorder of sex development. Journal of the College of Physicians and Surgeons Pakistan 201424 714-718.

12 Al-Agha AE, Thomsett MJ \& Batch JA. The child of uncertain sex: 17 years of experience. Journal of Paediatrics and Child Health 200137 348-351. (https://doi.org/10.1046/j.1440-1754.2001.00669.x)

13 Al-Jurayyan NAM. Ambiguous genitalia, two decades of experience: clinical management and sex assignment. Journal of Taibah University Medical Sciences 20105 13-20. (https://doi.org/10.1016/S16583612(10)70119-0)

14 Speiser PW \& White PC. Congenital adrenal hyperplasia. New England Journal of Medicine 2003349 776-788. (https://doi. org/10.1056/NEJMra021561)

15 Achermann JC \& Hughes IA. Pediatric disorders of sex differentiation. In Williams Textbook of Endocrinology 13th Edition, pp 893-963. Eds S Melmed, KS Polonsky, PR Larsen \& HM Kronenberg. Philadelphia, PA, USA: Elsevier, 2016.

16 Khajuria R, Walia R, Bhansali A \& Prasad R. The spectrum of CYP21A2 mutations in Congenital Adrenal Hyperplasia in an Indian cohort. Clinica Chimica Acta 201731 189-194. (https://doi. org/10.1016/j.cca.2016.11.037)

17 Rajput R, Bhansali A, Khandelwal N \& Radotra BD. Evolution of adrenal myelolipoma in a patient with congenital adrenal hyperplasia. Endocrinologist 200717 200-201. (https://doi. org/10.1097/TEN.0b013e31813e5f1e)

18 Falhammar H \& Torpy DJ. Congenital adrenal hyperplasia due to 21-hydroxylase deficiency presenting as adrenal incidentaloma: a systematic review and meta-analysis. Endocrine Practice 201622 736-752. (https://doi.org/10.4158/EP151085.RA)

19 Swaab DF. Sexual differentiation of the brain and behavior. Best Practice and Research Clinical Endocrinology and Metabolism 20073 431-444. (https://doi.org/10.1016/j.beem.2007.04.003)

20 Bonfig W, Roehl FW, Riedl S, Dörr HG, Bettendorf M, Brämswig J, Schönau E, Riepe F, Hauffa B, Holl RW, et al. Blood pressure in a large cohort of children and adolescents with classic adrenal hyperplasia (CAH) due to 21-hydroxylase deficiency. American Journal of Hypertension 201529 266-272. (https://doi.org/10.1093/ajh/hpv087)

21 Falhammar H, Frisén L, Hirschberg AL, Norrby C, Almqvist C, Nordenskjöld A \& Nordenström A. Increased cardiovascular and metabolic morbidity in patients with 21-hydroxylase deficiency: a Swedish population-based national cohort study. Journal of Clinical Endocrinology and Metabolism 2015100 3520-3528. (https://doi. org/10.1210/JC.2015-2093)

22 Falhammar H, Frisén L, Norrby C, Hirschberg AL, Almqvist C, Nordenskjöld A \& Nordenström A. Increased mortality in patients with congenital adrenal hyperplasia due to 21-hydroxylase deficiency. Journal of Clinical Endocrinology and Metabolism 201499 E2715-E2721. (https://doi.org/10.1210/jc.2014-2957)

23 Pergament E, Heimler A \& Shah P. Testicular feminisation and inguinal hernia. Lancet 1973302 740-741. (https://doi.org/10.1016/ S0140-6736(73)92579-8)
24 Ahmed S F, Cheng A, Dovey L, Hawkins JR, Martin H, Rowland J, Shimsura N, Tait AD \& Hughes IA. Phenotypic features, androgen receptor binding, and mutational analysis in 278 clinical cases reported as androgen insensitivity syndrome. Journal of Clinical Endocrinology and Metabolism 200085 658-665. (https://doi. org/10.1210/jcem.85.2.6337)

25 Castro CC, Filho GG, Calais FL, Coeli FB, Leal IR, Cavalcante EF, Monlleó IL, Pereira SR, Gabiatti JRE, Marques-de-Faria AP, et al. Clinical and molecular spectrum of patients with 17- $\beta$-hydroxysteroid dehydrogenase type 3 (17- $\beta$-HSD3) deficiency. Arquivos Brasileiros de Endocrinologia and Metabologia 201256 533-539. (https://doi.org/10.1590/S0004-27302012000800012)

26 Lee YS, Kirk JM, Stanhope RG, Johnston DI, Harland S, Auchus RJ, Andersson S \& Hughes IA. Phenotypic variability in $17 \beta$-hydroxysteroid dehydrogenase-3 deficiency and diagnostic pitfalls. Clinical Endocrinology 200767 20-28. (https://doi. org/10.1111/j.1365-2265.2007.02829.x)

27 Maimoun L1, Philibert P, Cammas B, Audran F, Bouchard P \& Fenichel P. Phenotypical, biological, and molecular heterogeneity of $5 \alpha$-reductase deficiency: an extensive international experience of 55 patients. Journal of Clinical Endocrinology and Metabolism 201196 296-307. (https://doi.org/10.1210/jc.2010-1024)

28 McCann-Crosby B, Schlomer B, Macias CG, Roth DR, Austin EG, Dietrich JE, McCullough LB, Karaviti L, Hicks MJ, Mansouri R, et al. State of the art review in gonadal dysgenesis: challenges in diagnosis and management. International Journal of Pediatric Endocrinology 2014 2014 4. (https://doi.org/10.1186/1687-9856-2014-4)

29 Bhansali A, Singh SK, Singh R, Kumar V, Khandelwal N \& Sialy R. Leiomyomata of the uterus presenting as an abdominal mass in a true hermaphrodite. Journal of Obstetrics and Gynaecology 200525 401-403. (https://doi.org/10.1080/01443610500137616)

30 Krob G, Braun A \& Kuhnle U. True hermaphroditism: geographical distribution, clinical findings, chromosomes and gonadal histology. European Journal of Paediatrics 1994153 2-10. (https://doi. org/10.1007/BF02000779)

31 Méndez JP, Ulloa-Aguirre A, Kofman-Alfaro S, Mutchinick O, Fernández-del-Castillo C, Reyes E \& Pérez-Palacios G. Mixed gonadal dysgenesis: clinical, cytogenetic, endocrinological, and histopathological findings in 16 patients. American Journal of Medical Genetics 199346 263-267. (https://doi.org/10.1002/ ajmg.1320460304)

32 Khandekar S, Dash S \& Dash RJ. 46XX male with dysgenetic testes. Journal of the Association of Physicians of India 199139 416-419.

33 Rizvi AA. 46,XX man with SRY gene translocation: cytogenetic characteristics, clinical features, and management. American Journal of the Medical Sciences 2008335 307-309. (https://doi.org/10.1097/ MAJ.0b013e31811ec1b4)

34 Valetto A, Bertini V, Rapalini E \& Simi P. A 46,XX SRY man with complete virilization and infertility as the main anomaly. Fertility and Sterility 200583 216-219. (https://doi.org/10.1016/j. fertnstert.2004.06.055)

35 Golalipour MJ, Ahmadpour-Kacho M \& Vakili MA. Congenital malformations at a referral hospital in Gorgan. Eastern Mediterranean Health Journal 200511 707-715.

Received in final form 29 January 2018

Accepted 31 January 2018

Accepted Preprint published online 31 January 2018 http://www.endocrineconnections.org

https://doi.org/10.1530/EC-18-0022
C) 2018 The authors

Published by Bioscientifica Ltd

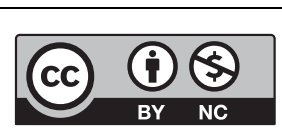

This work is licensed under a Creative Commons Attribution-NonCommercial 4.0 International License. 